\title{
Type B Aortic Dissection Treated with a Branched Aortic Arch Stent Graft and the STABILISE Technique Simple Abstract
}

\author{
Barral Pierre Antoine* \\ Barral Pierre Antoine, Assistance Publique, Hopital La Timone, Marseille France \\ *Corresponding author: Barral Pierre Antoine, Assistance Publique, Hopital La Timone, Marseille France
}

\section{ARTICLE INFO}

Received: 幽 October 03, 2020

Published: 幽 November 06, 2020

Citation: Barral Pierre Antoine. Type B Aortic Dissection Treated with a Branched Aortic Arch Stent Graft and the STABILISE Technique Simple Abstract. Biomed J Sci \& Tech Res 31(4)-2020. BJSTR. MS.ID.005147.

\section{ABSTRACT}

We report the case of a 57-year-old woman who presented with type B aortic dissection discovered by chance. The maximum aortic diameter was $70 \mathrm{~mm}$ in the proximal descending thoracic aorta. The entry tear was located at the aortic isthmus, and the proximal neck included all of the supra-aortic trunks. The dissection extended to the infrarenal aorta. The dissection was treated with a custom branched aortic graft with two branches, one for the innominate trunk and one for the left common , combined with the stent-assisted ballooninduced intimal disruption and delamination technique. This combined technique seems to provide a proximal seal zone and allow remodeling of the distal aorta in patients with type B aortic dissection without a proximal neck.

Keywords: Aortic Dissection; Branched Stent Graft; Stabilise

\section{Introduction}

Endovascular treatment is a minimally invasive, potentially curative approach for type $\mathrm{B}$ aortic dissection. The first-line endovascular technique is thoracic endovascular aortic repair (Tevar). However, Tevar alone results in total occlusion of the false lumen in $13-30 \%$ of cases, with a mortality rate of approximately $36 \%$ at 3 years [1,2]. Extensive residual dissection involving the aortic arch and abdominal aorta is still a major concern and a therapeutic challenge. Branched arch grafts have shown promising results [3]. The stent-assisted balloon induced intimal disruption and delamination (Stabilise) technique has also shown good results in the treatment of acute and chronic aortic dissection [4,5]. Here, we report a combined treatment for type B aortic dissection consisting of a branched aortic arch graft and the STABILISE technique.

\section{Case Report}

A 57-year-old woman presented with type B aortic dissection discovered by chance during examination for central facial paralysis. She had a history of ischemic stroke, which resulted in cognitive sequelae as well as left hemiparesis. Her cardiovascular risk factors included high blood pressure and insulin-requiring diabetes mellitus. She was first treated surgically for abdominal aortic rupture, occurring 3 days after diagnosis of the dissection, via conventional infrarenal abdominal aortic repair. There was a rapid increase in the size of the proximal descending thoracic aorta, with a maximal diameter of $70 \mathrm{~mm} 4$ months later (Figure 1). The dissection extended to the infrarenal aorta and to the proximal anastomosis of the aortic tube. The ascending aorta was $38 \mathrm{~mm}$ in diameter. The entry tear was $27 \mathrm{~mm}$ long and located at the aortic isthmus, and the proximal neck included all of the supraaortic trunks. A multidisciplinary aortic team including a vascular surgeon, a radiologist, a cardiologist and an anesthesiologist decided to perform an endovascular treatment with a custom branched aortic graft with two branches, one for the innominate trunk (IT) and one for the left common carotid artery (LCCA), combined with the STABILISE technique under general anesthesia in a multimodal angiographic suite (Discovery IGS 730, GE Healthcare, Chicago, USA). Cerebrospinal fluid (CSF) drainage was used to prevent medullary ischemic injury [6]. The left subclavian artery was reimplanted directly into the LCCA.

Bilateral transverse supraclavicular cervicotomy was performed to control the CCAs. Rapid pacing was used to ensure a precise, atraumatic landing and to avoid retrograde dissection [7]. Using a percutaneous approach, a tapered aortic endoprosthesis of $42 \times 26 \times 255 \mathrm{~mm}$ (Terumo Aortic $®$, formerly Bolton Medical $®$ ) 
was deployed under 2D/3D fusion imaging and transesophageal US to ensure localization in the true lumen. Orthogonal rings were used to precisely deploy the branched graft one centimeter before the IT and the LCCA [8]. A 10-F introducer sheath was inserted into the LCCA, and we catheterized the LCCA branch. To ensure localization in the stent graft branch and not between the aorta and the stent graft, we inflated a balloon in the stent graft branch, and we then deployed the tapered branch (13x8x90mm). A 10-F introducer sheath was placed into the right common carotid artery (RCCA) and we catheterized and deployed the tapered IT branch (13x17x80 mm) using the same technique (Figure 2$)$. We deployed a second stent graft up to $3 \mathrm{~cm}$ above the celiac trunk $(40 \times 40 \times 15 \mathrm{~mm})$ (W. L. Gore \& Assoc, Flagstaff, AZ). We deployed a bare stent $46 \mathrm{~mm}$ in diameter $\mathrm{x} 185 \mathrm{~mm}$ in length

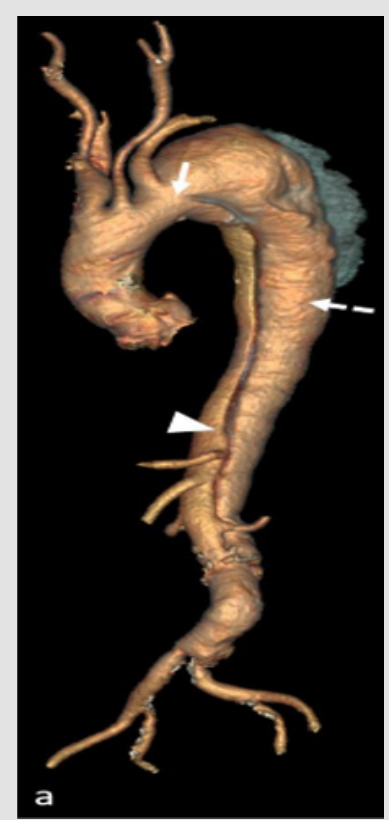

Figure 1: Angio-CT before the intervention showing the entry tear at the aortic isthmus (white arrow), the true lumen (white arrowhead), and the false lumen (white dotted arrow).

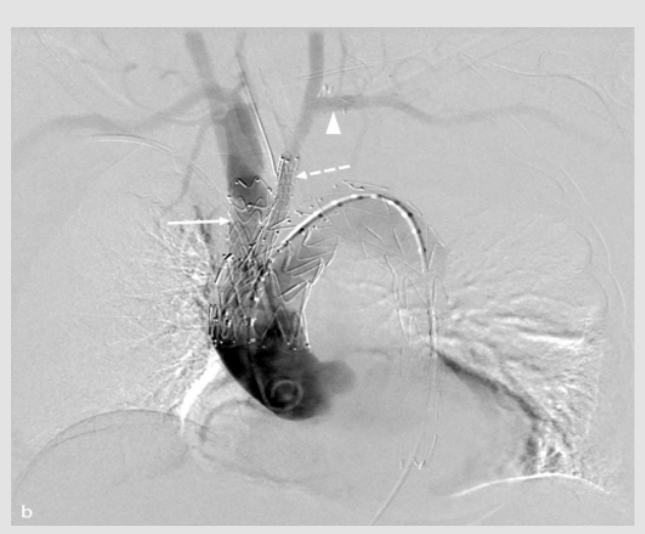

Figure 2: DSA-run showing the IT branch (white arrow), the LCCA branch (white dotted arrow), and the subclaviancarotid transposition (white arrowhead).
(ZDES; Cook Medical, Bloomington, Ind) up to the aortic bifurcation, and we ruptured the intimal flap using a Tri-Lobe balloon catheter and an inflation device. We used the aortic mask to determine when the balloon reached the size of the false lumen. The patient was extubated at the end of the intervention in the operating room. The procedure duration was $190 \mathrm{~min}$. The duration of fluoroscopy was $58 \mathrm{~min} 47 \mathrm{~s}$. The dose area product was $146.11 \mathrm{~Gy} . \mathrm{cm}^{2}$. The volume of contrast media used was $90 \mathrm{cc}$. Postoperatively, the patient received treatment with pressor amines, with an average blood pressure target of $100 \mathrm{mmHg}$. Two days after the procedure, she presented with paraparesis, which required extension of the CSF drainage up to 4 days, with a pressure target of $10 \mathrm{mmHg}$ [9]. She achieved complete recovery at 3 days. The hospitalization duration was 17 days, with a length of stay in the intensive care unit of 5 days. Angio-CT performed 8 days after the intervention showed complete thrombosis of the false lumen and patency of the IT, LCCA branches, celiac trunk, superior mesenteric artery and renal arteries (Figure 3).

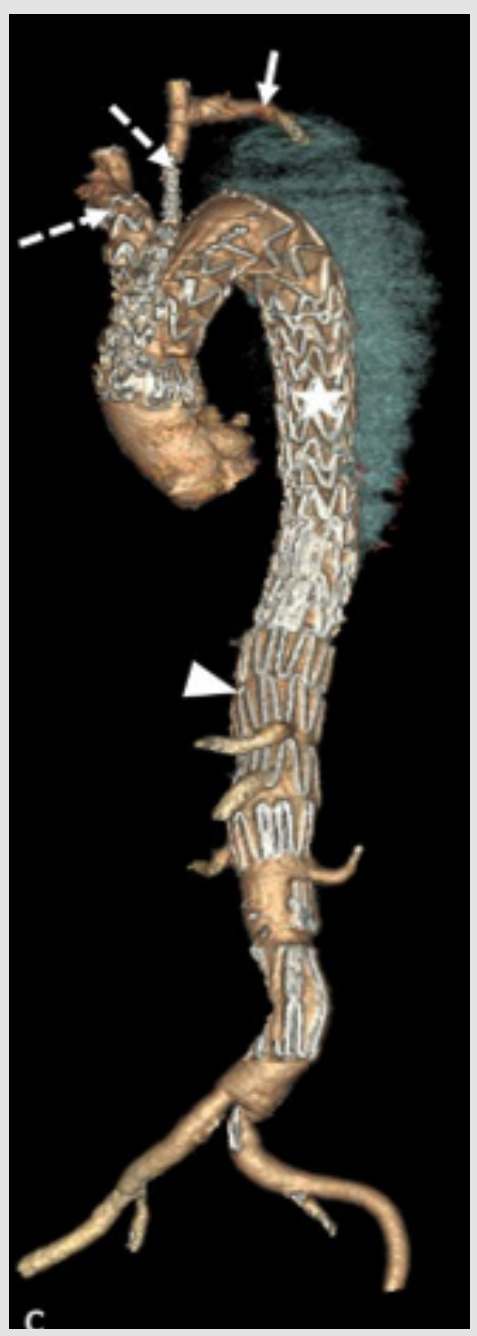

Figure 3: Angio-CT after the intervention showing the IT and CCA branches (white dotted arrows), the subclaviancarotid transposition (white arrow), the TEVAR (star), and the bare stent (white arrowhead). 


\section{Discussion/Conclusion}

Post dissection aortic aneurysms result from elevated pressure in the false lumen. Fenestrated and branched stent grafts in the aortic arch have been used in some expert centers to treat post dissection arch aneurysms, with an in hospital death rate of 5.3\%; possible complications include early type 1 endoleak (5.3\%) and cerebrovascular events (10.5\%), with the absence of late aorta-related mortality [3]. The Stabilise technique allows aortic remodeling in cases of acute and chronic type B dissection while not compromising the patency of collateral branches arising from the true lumen $[4,5]$. This novel combined technique seems to provide a proximal seal zone and allow both thrombosis of the thoracic aortic false lumen and remodeling of the distal aorta in patients with type B aortic dissection without a proximal neck.

\section{References}

1. Kang WC, Greenberg RK, Mastracci TM, Eagleton MJ, Hernandez AV, et al. (2011) Endovascular repair of complicated chronic distal aortic dissections: Intermediate outcomes and complications. J Thorac Cardiovasc Surg 142(5): 1074-1083.

2. Marques de Marino P, Oikonomou K, Verhoeven EL, Katsargyris A (2020) Techniques and outcomes of secondary endovascular repair for postdissection TAA/TAAA. J Cardiovasc Surg Torino 59(6): 767-774.

\section{ISSN: 2574-1241}

DOI: 10.26717/BJSTR.2020.31.005147

Barral Pierre Antoine. Biomed J Sci \& Tech Res

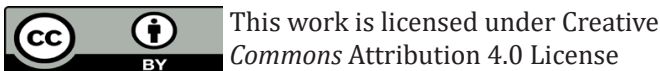

Submission Link: https://biomedres.us/submit-manuscript.php
3. Spear R, Hertault A, Van Calster K, Settembre N, Delloye M, et al. (2018) Complex endovascular repair of postdissection arch and thoracoabdominal aneurysms. J Vasc Surg mars 67(3): 685-693.

4. Faure EM, El Batti S, Abou Rjeili M, Julia P, Alsac JM (2018) Mid-term Outcomes of Stent Assisted Balloon Induced Intimal Disruption and Relamination in Aortic Dissection Repair (STABILISE) in Acute Type B Aortic Dissection. Eur J Vasc Endovasc Surg août 56(2): 209-215.

5. Faure EM, El Batti S, Sutter W, Bel A, Julia P, et al. (2020) Stent-assisted balloon dilatation of chronic aortic dissection. J Thorac Cardiovasc Surg :5222-5223.

6. Epstein N (2018) Cerebrospinal fluid drains reduce risk of spinal cord injury for thoracic/thoracoabdominal aneurysm surgery: A review. Surg Neurol Int 9(1): 48.

7. Bokoch MP, Hiramoto JS, Lobo EP, Shalabi A (2017) Rapid Ventricular Pacing for Landing Zone Precision During Thoracic Endovascular Aortic Arch Repair: A Case Series. J Cardiothorac Vasc Anesth 31(6): 2141-2146.

8. Koutouzi G, Sandström C, Roos H, Henrikson O, Leonhardt H, et al. (2016) Orthogonal Rings, Fiducial

9. Markers, and Overlay Accuracy When Image Fusion is Used for EVAR Guidance. Eur J Vasc Endovasc Surg 52(5): 604-611.

10. Rizvi AZ, Sullivan TM (2010) Incidence, prevention, and management in spinal cord protection during TEVAR. J Vasc Surg 52(4): 86S-90S.

$\begin{array}{ll}\text { BIOMEDICAL } & \text { Assets of Publishing with us } \\ \text { RESEARCHES } & \text { - Global archiving of articles } \\ & \text { - Immediate, unrestricted online access } \\ & \text { - Rigorous Peer Review Process } \\ & \end{array}$

